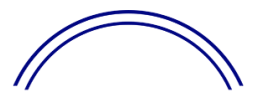

\title{
Forensic Psychiatry in Pakistan: An Update
}

\author{
Wajahat Ali Malik, ${ }^{1,2}$ Cameron Arnold, ${ }^{3}$ Ahila Vithiananthan, ${ }^{4}$ \\ Tariq Mahmood Hassan ${ }^{4,5}$
}

\begin{abstract}
${ }^{1}$ Advocate High Courts of Pakistan; ${ }^{2}$ National Action \& Coordination Group for Ending Violence Against Children, Pakistan; ${ }^{3}$ Department of Psychiatry, University of Toronto, Toronto, Canada; ${ }^{4}$ Department of Psychiatry, Queen's University, Kingston, Canada; ${ }^{5}$ Division of Forensic Psychiatry, Providence Care Hospital, Kingston, Canada
\end{abstract}

\begin{abstract}
Pakistan is a lower-middle income country in South Asia where forensic psychiatry is often not recognized as a distinct subspecialty of psychiatry. Although evolution toward this direction has begun, more development in this field is needed. Before Pakistan's Mental Health Ordinance of 2001, much of the mental health legislation and intitutional infrastructure pertaining to the mentally ill offender can be traced back to the Indian Lunacy Act of 1912. The past two decades have witnessed important legal developments in the role of psychiatry in Pakistan's criminal justice system. This has been seen through the devolution of health-care provision and by an extension of psychiatric service provision from the federation (federal government) to the four provinces. Despite the sparse resources allocated to psychiatry, competent yet scarce psychiatry residents are graduating from Pakistan's accredited residency programs with an interest in forensic psychiatry. The objective of this article is to reflect on the past, while examining the current state of existing forensic mental health in Pakistan. This article will also address the future trajectory of forensic psychiatry in Pakistan and supports the establishment of forensic psychiatry as a subspecialty in Pakistan.
\end{abstract}

Key Words: forensic psychiatry, mentally ill offender, criminal justice system, criminal responsibility, juvenile justice system, Pakistan

The Islamic Republic of Pakistan is a majority Muslim country in South Asia with a population of 220 million in a geographical land mass of $800,000 \mathrm{~km}^{2}$. Pakistan has four provinces (Sindh, Punjab, Khyber Pakhtunkhwa, and Baluchistan); two governments in charge of the Administrative Territories (Gilgit-Baltistan, Azad Jammu and Kashmir) and the Islamabad Capital Territory governed by the federal government. Pakistan has a rich history dating back a millennium with its judicial evolution having passed through three key stages: the Hindu rule, the Muslim rule, and the British colonial rule [1]. The fourth and current era began in 1947 following partition from British
India toward the establishment of Pakistan as an independent state [1].

\section{Forensic Psychiatry Training}

The College of Physicians and Surgeons Pakistan (CPSP) [2] regulates postgraduate medical education. In 1965, the Jinnah Postgraduate Medical Centre was the first fully accredited institution to offer a psychiatry residency training program. Today, 41 institutions have full accreditation for psychiatry residency training programs in Pakistan. Successful completion of the second part of the FCPS exam confers a Fellowship from the College of Physicians and Surgeons, Pakistan. In the final 
module, forensic psychiatry is documented as part of the overall syllabus. This requires the resident to have assessed under supervision 10 forensic patients overall and be trained in understanding:

1. The Mental Health Act,

2. administrative management of psychiatric cases,

3. forensic psychiatric syndromes,

4. psychiatrists' role in court,

5. management of violence and risk assessment, and

6. psychiatric report.

At this time in psychiatry, the CPSP offers further accredited training only in child and adolescent psychiatry.

\section{Mental Health Legislation in Pakistan}

Mental health legislation in Pakistan has witnessed significant changes over the past 20 years. Until 2001, Pakistan's mental health legislation was traced back to the Indian Lunacy Act of 1912. In 2001, a draft document was presented at the Pakistan's Psychiatric Society's biennial conference. This conference was attended by both United Kingdomtrained Pakistani psychiatrists alongside local Pakistani psychiatrists. This conference worked toward drafting the Mental Health Ordinance (MHO) 2001 [3]. The MHO was largely based on the United Kingdom's Mental Health Act of 1983 [4]. The MHO was issued in the form of a presidential order, with the purpose of changing the law to promote mental health, prevent deterioration of mental disorders, and appropriately care for those with mental health disorders [3]. The MHO defines a "mentally disordered prisoner" as someone who is detained in a psychiatric facility under the provisions of various criminal procedures, Prisoners Acts and under the Pakistan Air Force Act and Navy Ordinance [3]. The MHO allowed for secure forensic psychiatric facilities under the control of the Inspector General of Prisons [3].
Under the MHO 2001, the Federal Mental Health Authority was established with the aim of developing national standards for patient care. A board of visitors was formed to provide regular inspections and review the facilities to ensure a proper standard of care [3]. However, despite advances in the legislative framework, practice lagged behind.

In 2010, Pakistan's Constitution was updated after the 18th Constitutional amendment, which led to many changes, including devolving health from the Federal Mental Health Authority (federal control) to the provinces. It was deemed that the provinces would decide on the appropriate mental health legislation through their respective assemblies. Since the MHO 2001 was not passed by an act of parliament into law, it lapsed.

The southern province of Sindh took the initiative among Pakistan's four provinces in transitioning the MHO 2001 to the Sindh Mental Health Act 2013 (SMHA 2013) [5]. Its rules were enacted in 2014 to oversee the procedural matters required for compliance with the act's provisions [6].

In 2017, the Government of Sindh formed the Sindh Mental Health Authority under the provision of section 3(1) of the SMHA 2013, providing an institutional and bureaucratic infrastructure for the provision of forensic psychiatric services in the region [5]. Subsequently the Punjab Mental Health Act of 2014, Khyber Pakhtunkhwa Mental Health Act 2017 and Baluchistan Mental Health Act 2019 were established.

\section{Criminal Justice Legislation}

Pakistan's judiciary is divided into the superior and subordinate judiciary. The superior judiciary consists of the Supreme Court of Pakistan, five High Courts and the Federal Shariat Court. The subordinate judiciary comprises the civil and criminal courts. The judicial system in Pakistan combines remnants of British law and fundamental Islamic principles, which are intertwined in the judicial fabric of Pakistan. 


\section{Pakistan Penal Code 1860}

The Pakistan Penal Code 1860 (PPC) is the official criminal code of Pakistan, serving as a legal index and reference text for all criminal offences in the country [7]. Much of its content and structure was inherited from the Indian Penal Code established by Lord Thomas MacCauley in 1860 at the request of the British government [7]. The PPC was formalized following the creation of the Islamic Republic of Pakistan, following the Partition of India in 1947 [7].

\section{Criminal Responsibility}

Sections 82, 83, and 84 of PPC 1860 respectively provide legal provisions that mitigate the attribution of criminal responsibility under those circumstances where an offender is deemed to be a child or of unsound mind [7]. Children who are under 10 years of age are not held criminally responsible. If a child is younger than 14 years old, they would not be considered responsible for an offence only if it is deemed that they have an immature understanding of their conduct and its nature and consequences [7]. However, internationally accepted level of age of criminal responsibility ranges from 14 to 16 years old [8]. It is therefore of paramount importance that qualified individuals assess the child's emotional understanding, intellect and mental age in total. This would have an impact in determining the individual's fitness to stand trial and criminal responsibility.

\section{Criminal Procedure Code 1898}

The Criminal Procedure Code 1898 (CrPC 1898) establishes the rules that govern criminal procedure in Pakistani courts. The purpose of the CrPC 1898 is to provide formal guidelines for the legal consequences of criminal offences codified in the PPC 1860. Part VIII, Chapter XXXIV of the CrPC titled Lunatics describes the procedure of conducting a trial or inquiry in the case of a lunatic accused [9].

\section{Capacity to Defend}

An essential role of the criminal justice system is to determine whether those who are criminally charged are fit or competent to stand trial. In Pakistani law, fitness to stand trial is worded as "capacity to defend" [9]. Unlike most Western countries, the test for incapacity to defend in Pakistan is not laid out in the CrPC 1898 [9].

Section 464 of CrPC 1898 states that when a magistrate holding an inquiry or a trial has "reason to believe that the accused is of unsound mind and consequently incapable of making his defense," the magistrate will facilitate an inquiry into the mental status of the accused [9]. Typically, at the direction of the provincial government, a medical doctor, such as the Civil Surgeon of the district, writes a report for judicial proceedings [9].

Section 465 of the CrPC 1898 states that if an accused is deemed to be of unsound mind, incapable of articulating a defence, and deemed incapable during a Court of Session or a High Court trial, then further proceedings would be postponed [9].

Section 466 of CrPC 1898 provides a procedure for the release of the mentally ill offender for nonbailable offences during investigation or trial. The magistrate would ensure that such individuals would be in a safe environment in which they are unable to harm themselves or others [9].

\section{Not Criminally Responsible Disposition}

Section 470 of CrPC 1898 stated that if a mentally ill offender is acquitted on "grounds of lunacy," then "the finding shall state specifically whether he committed the act or not." Similarly, section 471 of CrPC 1898 states that if it is mentioned that the mentally ill offender committed the alleged act, then the magistrate or court can "order such a person to be detained in safe custody in such place and manner as the Magistrate or Court thinks fit," unless the patient is not detained under the Lunacy Act 1912 [9]. It is interesting to note that the CrPC 1898 still refers to the outdated Lunacy Act 1912.

\section{Qanun-e-Shahadat Order 1984}

Rules and regulations related to legal evidence in Pakistani courts are codified in The 
Qanun (Law)-e-Shahadat (Evidence) Order 1984 (QSO). This replaced the Evidence Act of 1872 [10]. The purpose was to harmonize legal evidentiary requirements with the injunctions of Islam according to the Quran and Sunnah (acts of the Prophet Muhammad, peace be upon him) [10].

Articles 59-65 of the QSO 1984 outline the role of expert witnesses, whose skills and judgment were sought out in the context of adjudicating certain crimes, such as those where the accused may be suffering from a mental disorder. According to the QSO 1984, the court can ask a medical professional, such as a psychiatrist with experience in forensic assessments, as an expert witness to give their opinion about the extent to which the accused was capable of appreciating the nature of the act committed or its moral wrongfulness at the time of the alleged crime [10]. Educating resident trainees on how to be an expert witness, and how to determine if a person is criminally responsible, capable and fit to stand trial are important if forensic psychiatry fellowships are to become a part of psychiatry residency training in Pakistan.

\section{Juvenile Justice System Act 2018}

Pakistan amended laws about youth who come into contact with the criminal justice system. The Juvenile Justice System Order 2000 was in effect until 2018 when changes were made to make way for the Juvenile Justice System Act (JJSA) 2018 [11]. The act specifies a procedure for the provision of safeguards in cases of juveniles, who are younger than 18 years of age. These individuals may have an immature understanding of the nature of their actions at the time of their offence. The law provides that the investigation in cases of juveniles will be completed with help from a social welfare officer [11]. The social welfare officer prepares a social investigation report to be included with the police report submitted to the court [11]. The social investigation report describes the juvenile's character, education, social and moral background, along with any evidence of the offence by the juvenile and the possibility of sending the juvenile to a juvenile rehabilitation centre or release on probation for their psychosocial treatment or psychotherapy [11]. The report also includes all legal and appropriate assistance provided to the juvenile for their understanding, concept and consequences [11].

JJSA 2018 also states that if a juvenile before the court is suffering from serious physical or mental illness, the court will send them to a hospital or a medical institution where treatment will be given to the juvenile at the expense of the state. This new law takes into consideration a juvenile's young, immature mind and supports the rehabilitation of these individuals into society when they commit criminal offences.

\section{The Criminal Justice System of Pakistan}

\section{Police}

The Pakistan Police Order of 2002 replaced the Police Act of 1861. It includes a set of roles and responsibilities for the Pakistani police. As part of their remit to manage those experiencing mental illness in the public, the Police Order 2002, Chapter II (responsibilities and duties of the police, section $4 q$,) directs the police to "take charge of lunatics at large to prevent them from causing harm to themselves or other members of the public and their property" [12]. However, as part of their training, there is no mention in the Police Order 2002 on police needing basic mental health training to triage those offenders as potentially having mental health problems, including juvenile offenders, and how to best manage this vulnerable group [12]. It is important for police to consult with mental health professionals to be well equipped to properly assess and care for mentally ill offenders. In the future, it would be valuable to build bridges between police, lawmakers, judiciary and mental health professionals to better care for mentally ill offenders.

In Pakistan, civil society and the state have made unprecedented efforts to promote a 
preventive and reformative approach to justice. This has led to an increased awareness among justice actors - the police in particularabout the important role that forensic mental health plays in the justice process, how it contributes to rule of law, and how it may prevent reoffending.

Group Development Pakistan (GDP) is one of the civil society organizations that has been contributing to this slow but undeniable forensic mental health revolution in Pakistan. Since 2018, GDP has been training police officers who may deal with children in contact with the law. The capacity-building program provides police officers with adequate forensic communication skills to avoid secondary victimization of a child during the investigation process or while in detention, and enable the child to provide coerced-free evidence [13].

This process has been complemented by the establishment of 13 pilot child courts by the higher judiciary (with technical support from GDP and financial help from the British High Commission). These child courts have been designed and rehabilitated to provide a child-conducive environment in line with international child safeguarding standards. The judges, court staff, lawyers, and prosecutors in these child courts are also trained and coached on forensic communication to guarantee the child a gender-sensitive process, where the child will feel listened to, safe, and considered. The need to assess the child's psychological capacity to face trial or testify is also part of the training process.

This focus on forensic mental health for child and gender justice has created a multiplier effect. A juvenile police unit has been established in the northern city of Peshawar, Khyber Pakhtunkhwa in April 2021, while the police in the federal capital of Islamabad has created a gender protection unit to deal with those cases involving children. These specialized police units follow language and standard operating practices that recognize the specific needs of children and provide a physically and psychologically safe environment that will promote the rule of law and child justice in line with international child rights standards. These efforts in Pakistan have been acknowledged by the United Nations Special Rapporteur to the Secretary General on Violence Against Children, Dr. Najat Maalla M'jid. They underline the need to increasingly work at a cross-sectoral level, where justice actors collaborate with child protection specialists and forensic mental health experts [14].

The model piloted in Pakistan shows that positive change is possible. These structures led to increased efforts to keep children away from detention, improve access to justice for girls, unprecedented mobilization of justice actors to reform and protect children, and increased gender and child sensitive jurisprudence coming out of these courts.

\section{Judiciary}

In Pakistan's criminal justice system, lawyers and judges are essential in the provision of forensic psychiatric services. Where there is uncertainty about an offender's mental status at the time of the crime, the judge refers the case to a medical superintendent, which is then forwarded to the respective psychiatry department for a formal assessment. A committee will then examine the case and prepare a report. This report is based on the clinical assessment provided by an attending psychiatrist. The psychiatrist will determine if there is a clinical diagnosis and comment on the defendant's capacity and criminal responsibility at the time of the crime. The report is then forwarded to the medical superintendent of that institution, who then addresses the court with the findings of the committee. A forensic psychiatric assessment can be requested either directly by the court or through an application made to the court by the defence counsel.

\section{Prison}

For the mentally ill offender, postconviction sentencing is primarily concerned with confinement, with few resources available for treatment and rehabilitation. In some circumstances, the offender may be transferred to 
a medical facility for treatment for part or all of their sentence under Part VI (removal of prisoners), section 30 of the Prisoners Act of 1900 [15]. In most central prisons, a separate block in the prison is designated for patients with comorbid psychiatric or behavioural problems. A postgraduate psychiatry trainee from a tertiary care facility interviews the patients on this block every week for the pupose of assessment and management. If the trainee has concerns, a senior consultant may perform their own independent assessment. Alternatively, the trainee, in consultation with a senior faculty member, may have a patient transferred to a tertiary care facility, in which a team of three senior consultants assesses the patient. A detailed assessment is subsequently forwarded to the sessions judge of the district judiciary as well as the prison authorities [16]. It is important for trainees to learn from senior consultants how to perform thorough assessments, so appropriate and timely consultations can take place. It would be useful for trainees to learn these strategies before conducting assessments.

There is no official systematic collection of data about the number of mentally ill people confined in Pakistan's prison system. Anecdotal evidence from mental health professionals working there suggests that psychiatric morbidity in prisons may be increasing. One study found $62.50 \%$ of female inmates to be suffering from psychiatric illnesses, $23.43 \%$ suffered from affective disorders and $10.15 \%$ from anxiety-related illnesses [17]. This study was conducted in a female prison. The data cannot be extrapolated to male inmates. Further study is needed for male inmates.

On October 1, 2017, all provincial home departments except in former Federally Administered Tribal Area shared official data about the prison population of Pakistan [18]. There were 84,287 Pakistani prisoners in 112 prisons when the authorized official capacity was 53,744 [18]. Prison occupancy rate was at $157 \%$ capacity [18]. The occupancy rate of prisoners was highest in Punjab at $168 \%$, followed by Sindh at $155 \%$. The data further revealed that 1,343 out of 84,287 prisoners $(1.6 \%)$ were juveniles and $90 \%$ of the juvenile prisoners in prisons were under-trial prisoners [18].

Overcrowding in prisons has been associated with substandard and inhumane conditions of detention, including poor nutrition, insufficient water, inadequate accommodation, poor access to health care, lack of hygiene, barriers to family visitation, lack of staff, and safety and security concerns [18]. It is important to address overcrowding in prisons and the need for appropriate diversions to rehabilitation programs to avoid these negative outcomes.

\section{Forensic Psychiatry: Provisions, Challenges and the Path Ahead}

In 2015, Dr. Tariq Mahmood Hassan published the first comprehensive paper on forensic psychiatry in Pakistan. Since then, he has lectured at psychiatric conferences in Pakistan and to the judiciary in 2019 at the Islamabad High Court Bar Association. In 2019, on his recommendation, the Pakistan Psychiatric Society (PPS) agreed in principle to develop a forensic psychiatry section within the PPS. The section includes local and international Pakistani forensic psychiatrists [2]. This was officially confirmed by the then president of the PPS, Prof. Dr. Iqbal Afridi, on December 24, 2020.

New developments in the field of forensic psychiatry are essential as psychiatrists are under immense public pressure to assess the criminal responsibility of blasphemy offences. Section 295-B of the PPC 1860 forbids defiling the Quran and section 295-C of PPC 1860 forbids using derogatory remarks against the Prophet Muhammad (peace be upon him) [7]. These types of offences tend to receive the most international coverage when the accused is suspected of having a mental illness. In some cases, a fringe section of the public demand their own form of justice against the accused, which can have fatal consequences. According to the PPC 1860, there are no specific criteria for mentally ill offenders violating these Islamic laws [15]. Future challenges 
to the current law will allow for clarification and possibly amending the current statute for the mentally ill offender.

The judiciary has yet to formalize and implement a mechanism to screen pretrial accused for mental illness. Capacity to defend and criminal responsibility assessments are rare and only happen in institutions where the psychiatrist has a sharp interest in the field and the local judiciary is open to changes in practice. Otherwise, the majority of work by psychiatrists in this field includes caring for the postconvicted mentally ill offender under the jurisdiction of the local prison authorities.

However, in February 2021, Pakistan's evolution in forensic psychiatry took a multigenerational leap forward. Ms. Safia Bano and others were appealing to the Supreme Court in Pakistan that certain legal procedures were not followed in trials taking into account their mental illness. In another case, but part of the same judgment, the concern of carrying out the death penalty on a mentally ill sentenced person was also brought up.

In their landmark judgment, the Supreme Court of Pakistan made numerous important decisions (19). The first line of the judgment states "the mental health of a person is as important and significant as his physical health." The first matter that was addressed was the definition of mental illness, avoiding narrow definitions and using the International Classification of Diseases, published by the World Health Organization.

Second, the Supreme Court directed that all terms like "unsound mind" should be replaced with "mental disorder" or "mental illness." Similarly, the term "lunatic" would also be substituted appropriately.

Third, the matter of a person's capacity to defend should be taken seriously, keeping in mind procedural fairness and due process guaranteed under the constitution and the law.

Fourth, once the court has formed a prima facie opinion that the accused may be incapable of making their defence, the court has a duty to seek a medical opinion by forming a medical board.

Fifth, court reports must not merely be a diagnosis but a detailed and structured account of the individual with specific reference to psychopathology.

Lastly, in the decision that made worldwide news, the Supreme Court of Pakistan set a new legal threshold on the criteria to execute the sentenced mentally ill person. In its judgment it states that "we hold that if a condemned prisoner, due to mental illness, is found unable to comprehend the rationale and reason behind his/her punishment, then carrying out the death sentence will not meet ends of justice." However, the court clarified that "not every mental illness shall automatically qualify from an exemption from carrying out the death sentence." It states that a medical board will make such clinical assessments to certify that the condemned prisoner no longer has the higher mental functions to appreciate the rationale and reasons behind the sentence of death awarded to them.

\section{Conclusion}

Pakistan is at a watershed moment where the disciplines of psychiatry and the law are beginning to build bridges. With greater cooperation among the police, judiciary, prison department, nongovernmental organizations, and psychiatry, the country can begin to gradually implement key processes to support mentally ill offenders. The existing liaison between the legal and psychiatric professions must be enhanced. The judiciary, police, and the psychiatric community need a process of ongoing education and training for their awareness and implementation of the legislation as it relates to the mentally ill offenders. More research, particularly epidemiological studies, will help better understand the scale of the problem at hand, both within and outside prisons.

The overall goal is to ensure protection of the public while safeguarding the dignity and 
human rights of mentally ill offenders. International institutions can help by opening their doors to Pakistani FCPS graduates interested in gaining the necessary forensic competencies to develop this subspecialty. Pakistan's landmark Safia Bano judgment brings with it the weight of the law to ensure the rights of the mentally ill accused and sentenced persons are kept in the fore.

Acknowledgements: We thank Valerie Khan, Executive Director of Group Development Pakistan for her contribution to the manuscript.

\section{Conflict of Interest: none}

\section{References}

1. Hussain F. The Judicial System of Pakistan. Islamabad: Federal Judicial Academy; 2015. https://www.supremecourt.gov.pk/downloads judgements/all_downloads/Judicial_System of Pakistan/thejudicialsystemofPakistan.pdf.

2. College of Physicians and Surgeons Pakistan. Karachi: CPSP, n.d. https://www.cpsp.edu.pk.

3. Government of Pakistan. Mental Health Ordinance. Islamabad: Government of Pakistan Printing Press; 2001. http://punjablaws.gov.pk/laws/430a.html.

4. Tareen A, Tareen K. Mental health law in Pakistan. British Journal of Psychiatry International. 2016;13(3):67-69. https://www.cambridge.org/core/journals/ bjpsych-international/article/mental-health-lawin-pakistan/92791134964FDEAA7FC6DAC02 CAD6543.

5. Sindh Mental Health Act, 2013. http://www.pas.gov.pk/index.php/acts/details/ en/31/237.

6. The Sindh Mental Health Rules. Karachi: Government of Sindh; 2014. http://sindhlaws.gov.pk/setup/publications SindhCode/PUB-15-000271.pdf.

7. Pakistan Penal Code, Act XLV of 1860 (Updated on 06 May 2018). http://nasirlawsite.com/laws/ppc.htm.

8. UNCRC Committee's General Comment No. 24 (2019) on Children's Rights in the Child
Justice System [adopted on September 18, 2019]. https://tbinternet.ohchr.org/Treaties/ CRC/Shared\%20Documents/1 Global/ CRC_C_GC_24_8968_E.docx.

9. The Pakistan Code. The Code of Criminal Procedures, 1898.

http://pakistancode.gov.pk/english/ UY2FqaJw1-apaUY2Fqa-apea-sg-ijijijijijijij.

10. Qanun-e-Shahadat Order, 1984. https://punjabpolice.gov.pk/system/files/qanune-shahadat-order-1984.pdf.

11. Juvenile Justice System Act, 2018. http://www.na.gov.pk/uploads/ documents/1519296948 886.pdf.

12. Government of Pakistan. Police Order, 2002 (chief executive's order no. 22 of 2002). http://npb.gov.pk/wp-content/uploads/2014/08/ police order 2002.pdf.

13. Group Development Pakistan, American Bar Association. Representing child victims: training manual for legal aid lawyers. https://gdpakistan.org/wp-content/ uploads/2021/04/Training-Manual-for-Legaland-Lawyers.pdf.

14. Federal Ministry of Law and Justice, Terre des hommes Foundation, BackerMcKenzie, the office of the UNSRSG on VAC, Penal Reform International, International Association of Youth \& Family Judges and Magistrates, et al. National Preparatory Consultation on Justice with Children (2021). https://gdpakistan.org/ wp-content/uploads/2021/02/World-Congresson-Justice-with-Children-Meeting-NotesJan 2021.pdf.

15. The Prisoners' Act, 1900. http://punjablaws.gov.pk/laws/17.html.

16. Hassan T, Nizami AT, Hirji S. Forensic psychiatry in Pakistan. International Journal of Law and Psychiatry. 2015;41:95-104. https://www.sciencedirect.com/science/article/ abs/pii/S016025271500076X?via\%3Dihub.

17. Bilal F, Saeed K. Psychiatric morbidity among the female inmates of District Jail Adyala, Rawalpindi. Rawal Medical Journal. 2011;36(2):129-132. https://www.ejmanager. com/mnstemps/27/27-1297006596. pdf?t=1570003627. 
18. Cursor of Development and Education Pakistan, National Counter Terrorism Agency Pakistan, International Committee of the Red Cross. Addressing overcrowding in prisons by reducing pre-conviction detention in Pakistan. 2018. http://codepak.org/ wp-content/uploads/2018/05/Addressingovercrowding-in-prisons-by-reducing-preconviction-detention-in-Pakistan.pdf.
19. Supreme Court of Pakistan. In the Supreme Court of Pakistan (Review Jurisdiction) 2021. https://www.supremecourt.gov.pk/downloads judgements/c.r.p._420_2016.pdf.

\section{Corresponding author}

Dr. Tariq Mahmood Hassan, Division of Forensic Psychiatry, Providence Care Hospital, 752 King St. West Kingston, ON K7L 4X3 Canada - email: hassant@providencecare.ca 